\title{
Overview of Acoustic and Sonic Boom Advancements During Development of NASA Launch Vehicles
}

And How We Couldn't Have Done It Without Ken Plotkin

Jess Jones, Darren Reed, Tom Nesman, Janice Houston, Bruce Vu, Jeremy Kenny

Acoustical Society of America 


\section{Overview}

- $\quad$ This presentation reviews several testimonies from Marshall Space Flight Center (MSFC) and Kennedy Space Center (KSC) engineers who worked with Ken Plotkin

- Jess Jones (ASRI, retired MSFC engineer from vehicle structural dynamics and acoustics)

- Darren Reed (MSFC engineer: launch vehicle acoustics and propulsion dynamics)

- Tom Nesman (MSFC assistant branch chief: propulsion fluid dynamics)

- Janice Houston (MSFC engineer: formally launch vehicle acoustics)

- Jeremy Kenny (MSFC team lead: launch vehicle acoustics and stability)

- Bruce Vu (KSC engineer: ground system launch acoustics) 


\section{From Jess Jones, Tom Nesman, and Janice Houston}

Jess and Tom: I started working with Ken Plotkin in the mid 1960's and early 1970's while he was with Wyle Laboratories. I had just got started working acoustic environmental issues for NASA/MSFC during those days. This was during the Saturn/Saturn V Vehicle Development Programs at MSFC and the early design work for the Space Shuttle Vehicle. The most notable work, at this time, that Ken help us with was the prediction of in-flight fluctuating environments for vehicle systems; Re: 1 . We used this work extensively during the subsequent years.

- Re: 1) Plotkin, Kenneth J., and Robertson, J. E., "Prediction of Space Shuttle Fluctuating Pressure Environments, Including Plume Effects", Wyle Laboratories, Report WR 73-6, June 1973.

- Plotkin, Kenneth J., "Shock Wave Oscillation Driven By Turbulent Boundary Layer Fluctuations", Wyle Laboratories, Report WR 72 12, September 1972.

- Plotkin, Kenneth J., "Prediction of Fluctuating Pressure Environments Associated with Plume-Induced Separated Flow Fields", Wyle Laboratories, Report WR 73-3, May 1973.

- $\quad$ As we got more involved with the Space Shuttle Vehicle development in the early 1970's the Sonic Boom issue began to be of concern. It was at this time that I got more involved with this issue and I began to make predictions of the Sonic Boom Environment during Space Shuttle Entry over the continental United States on its return from Orbit to the Kennedy Space Center (KSC). A working group was formed to address the Sonic Boom with members from Langley, JSC, Ames and MSFC. I was the one who made the prediction of the Sonic Boom over the Continental United States due to Orbiter Reentry. I was working with a Group at Ames at that time. Ken became involved with us later to address the Orbiter maneuvering effect (turning/banking/acceleration). Measurements were made during the Ascent of the Saturn V Launch of Apollo 15, 16 and 17 Missions. This was used to gain more confidence in our predictions techniques. It was at this time that more attention was now being made on the Space Shuttle Orbiter entry maneuvers (turning/banking/acceleration) during the approach to the landing site at KSC. I was able to get funding and had Ken (Wyle Laboratories) address the issue of Sonic Boom focusing during maneuvers; Re: 2.

- Re: 2) Plotkin, Kenneth J. and Cantril, Jerry M., "Prediction of Sonic Boom at a Focus", Wyle Research Report WR 75-7, October 1975. Also AIASA Paper 76-2 January 1976. 


\section{From Jess Jones, Tom Nesman, and Janice Houston (Cont.)}

- $\quad$ This might have been Ken's first entry into Sonic Boom Theory, although Ken had publish some on the propagation of weak shock waves in the atmosphere before this time. Ken continued this work and is now known nationally/internationally in Sonic Boom and is highly respected. In the later years Ken told me "See what you started". I approached Ken again in the early 1993 during the investigations concerning the Nation Launch System (NLS) that NASA was considering at that time, to help us develop a PC Version for Sonic Boom Prediction.

- I am very pleased and honored to have known Ken and worked with him over the years.

- $\quad$ Janice Houston: Ken helped us with acoustic measurements of the ALV-XI launch vehicle (from Wallops) by letting us borrow microphone stands. He was always a good collaborator. We had an informal book club - he liked science fiction (and Janice is a nerd so that worked)

- $\quad$ Ken meant a lot to me - I was always surprised (pleasantly) on how well we got along. Even through tough times (professional / personal life) he kept his humor. He will be missed. 


\section{From Darren Reed (01/05/17)}

- $\quad$ Ken did most of the sonic boom analyses for the X-33 and X-34 programs. He developed a moving rocket noise program that could map the noise levels around the launch stand.

- $\quad$ One thing I remember about the "moving rocket noise" work that Ken did during the X-33 days is that as you would expect the noise levels become more circular as the rocket ascends. The simple programs that Doug and I used were totally based on ground measurements which biased the noise towards the duct side. As the rocket ascends it becomes more circular as you would expect. This increased the levels slightly away from the trench. It even slightly increases the levels in the direction of travel as the vehicle tip towards its flight path.

- $\quad$ The main work he did for X-33 sonic boom was incorporating the near-field CFD pressure data into the shape factor used in calculating the sonic boom footprints (on ground pressures). The other big part of the sonic boom work was pulling the footprint data into mapping software to show the footprints with respect to towns, roads, and protected wildlife areas. That was one of the more tedious efforts because the Environmental Engineering groups kept changing what they wanted. We probably redid that work at least 10 times - very irritating. The X-33 funding allowed Ken to improve the PCBoom program: better graphics, better memory management, faster processing, and more output options.

- "X-33 Advanced Technology Demonstrator Vehicle Program Final Environmental Impact Statement Volume I", NASA Report NP-1997-09-02-MSFC, September 1997.

- "Sonic Boom Prediction Methodology for Environmental Assessment of X-33”, Wyle Laboratories, Report TN 99-02, May 1999.

- Plotkin, Kenneth J., “X-34 Sonic Boom Assessment”, Wyle Laboratories, Report WR 99-13, June 1999.

- If NASA didn't completely take advantage of these improvements, it was passed on to the Air Force and other commercial entities. 


\section{From Jeremy Kenny (06/19/17)}
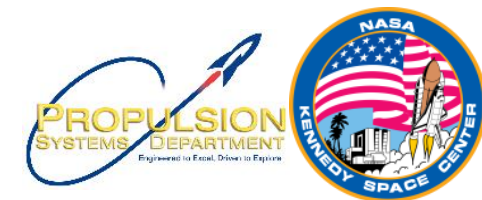

- $\quad$ I first met Ken Plotkin in 2007 through a NASA contract using Wyle services to measure the free field acoustics of the Space Shuttle Solid Rocket Booster (RSRM). This was my first major project starting at NASA and we relied heavily on Wyle to support us with measurement expertise, as well as data processing and just helping us understand what the heck we were measuring! Ken worked primarily on the software LFIRE, which stands for Solid Rocket Motor Longitudinal Firing Acoustic Prediction Software. This software predicted sound pressure levels at given locations while accounting for ground effects, atmospheric absorption, and plume source information. It is an excellent program and allowed better understanding / correction of the RSRM acoustic data we were measuring.

- "LFIRE: Solid Rocket Motor Longitudinal Firing Acoustic Prediction Software”, Wyle Memo Job \#T55040, January 2009.

- $\quad$ Ken helped us prepare for and successfully measure the RSRM free field acoustics for three static tests - a first in NASA launch vehicle acoustics history. It was a work span of over 2 years that I got to work with Ken and Wyle Labs; a great first 2 years of my career.

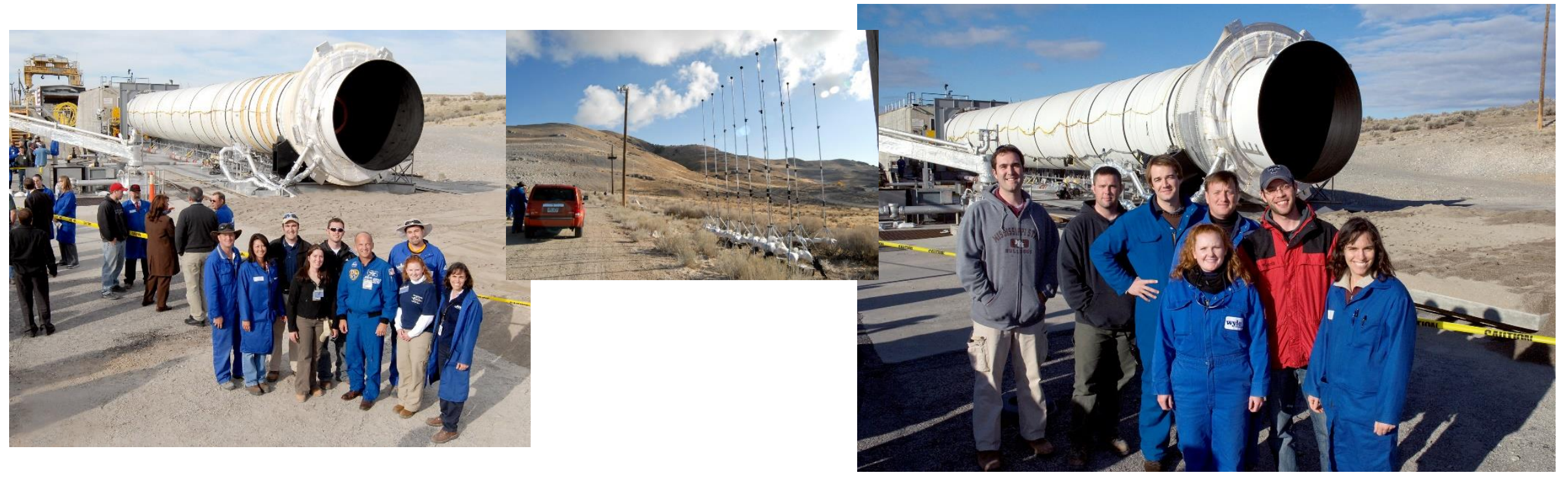

- My time with Ken Plotkin was great - I always learned from his experience and benefited from his wisdom. He will be missed. 


\section{From Bruce Vu (06/19/17)}

- $\quad$ Ken Plotkin worked with Kennedy Space Center (KSC) engineering on two launch vehicle development programs - the Ares I and the SLS EM-1. During both programs, Ken worked with Bruce Vu to develop the PAD software package, which gives near-field rocket noise predictions for the launch pad and surrounding structure. PAD was first created for the Ares I program, leveraging acoustic data collected during the Ares Subscale Model Acoustic Test (ASMAT) program. After several version updates, Ken then used PAD to support the SLS ground acoustic predictions, with updates taken from the SLS Model Acoustic Test (SMAT) program. The software accommodated for multiple propulsion system noise sources, plume impingement, 3D diffraction, and directivity. Evolution of PAD, and the successful relationship with KSC lasted over 5 years.

- Plotkin, Kenneth J., "Space Launch System Model Acoustic Test (SMAT) Support and PAD V3.4", Wyle Research Report WR 13-18, December 2013.

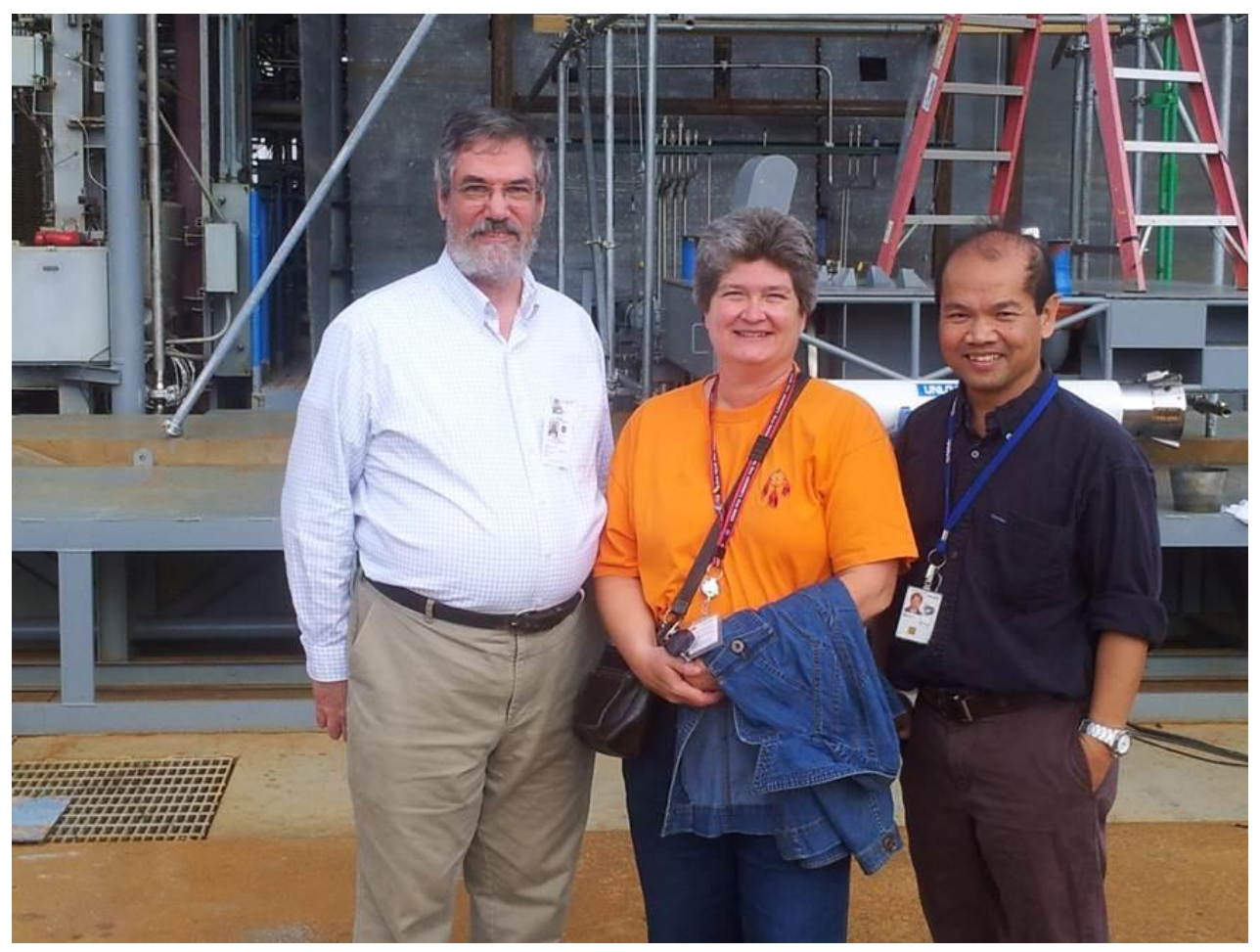


On behalf of all the co-authors, thank you for inviting us to share our thoughts about Ken Plotkin and how he impacted NASA through his lifetime 